\title{
THE BILATERALITY \\ OF IDIOPATHIC CARPAL TUNNEL SYNDROME AMONG MANUAL WORKERS
}

\author{
MAGDALENA LEWAŃSKA \\ Nofer Institute of Occupational Medicine, Łódź, Poland \\ Department of Occupational Diseases and Environmental Health
}

\begin{abstract}
Objectives: To evaluate: a) the prevalence of bilateral idiopathic carpal tunnel syndrome (CTS) in manual workers; b) a correlation between the duration of unilateral and bilateral CTS symptoms; c) a correlation between the onset of CTS symptoms in the unilateral dominant/non-dominant hand and the time of developing bilateral CTS; and d) findings of the nerve conduction study (NCS) in symptomatic and asymptomatic hands of patients with unilateral CTS. Material and Methods: Clinical and neurophysiological examinations were conducted along with a detailed analysis of job exposure of 332 manual workers admitted to the Occupational Medicine Department, the Nofer Institute of Occupational Medicine, with suspected occupational CTS. Eventually, 258 patients were excluded from the study: 34 with associated neuropathies and 206 with other conditions potentially associated with CTS. Cases with work-related CTS (18) were also excluded. Results: A total of 74 patients were diagnosed as idiopathic CTS. In idiopathic CTS, the right hand was affected in $15(20.3 \%)$ patients, the left hand in $4(5.4 \%)$ patients, and both hands in 55 (74.3\%) patients. Symptoms duration was longer in the patients with bilateral CTS (4.01 years) than in those with a unilateral right $(1.7$ years, $p=0.002)$ or left hand condition ( 2.8 years, $p=0.313$ ). Median nerve impairment at the wrist was revealed by NCS in 6 left and 2 right asymptomatic hands. Conclusions: The findings of the study indicate the need for "alerting" patients with unilateral CTS about the risk of the disease developing in the contralateral hand. Therefore, NCS should be routinely performed in the asymptomatic hands of patients with unilateral CTS, which is essential for the prevention of neuropathies, especially among manual workers performing repetitive manual tasks. Int J Occup Med Environ Health. 2020;33(2):151-61
\end{abstract}

Key words:

syndrome, CTS, idiopathic, tunnel, carpal, bilaterality

\section{INTRODUCTION}

Carpal tunnel syndrome (CTS) is the most common upper limb entrapment neuropathy which occurs more frequently in the dominant hand, both among right and lefthanded persons [1]. Thus, one can presume that the daily activity of the dominant hand is a factor contributing to CTS laterality. However, CTS is often a bilateral disorder, especially when related to an underlying medical condition or a risk factor such as obesity [2,3]. Stanek and
Pransky [4] reported 23\% patients with bilateral CTS and a coexisting systemic condition related to the disorder, and $12 \%$ unilateral ones.

In fact, CTS is the leading cause of work-related upper extremity musculoskeletal disorders associated with certain tasks including repetitive hand motions, awkward hand positions, strong gripping, mechanical stress on the palm, and the use of vibrating hand tools. An occupational origin of CTS is recognized after excluding any coexisting

Funding: this study was supported by the Ministry of Health, Poland (project No. IMP 12.9/2010, entitled "Impact of occupation exposure on the prevalence of carpal tunnel syndrome with special reference to computer-users," project manager: Magdalena Lewańska, M.D., Ph.D.)

Received: July 15, 2019. Accepted: November 4, 2019.

Corresponding author: Magdalena Lewańska, Nofer Institute of Occupational Medicine, Department of Occupational Diseases and Environmental Health, św. Teresy 8, 91-348 Łódź, Poland (e-mail: Magdalena.Lewanska@imp.lodz.pl). 
medical conditions and evidence of positive association symptoms with long-lasting work exposure to biomechanical risk factors (such as repetition, force and vibration especially when put together). The lateral character of occupational CTS is significantly related to hand dominance and work exposure. It is also known that symptoms of occupational CTS as well as asymptomatic neurographical signs of median neuropathy at the wrist can change over time. They can be reversible following a period of less repetitive work [5].

It is estimated that $50 \%$ of patients suffer from idiopathic CTS [6] but little is known on the prevalence of bilateral idiopathic CTS. To the best of the author's knowledge, there are only 2 studies investigating bilateral symptoms in idiopathic median neuropathy at the wrist $[7,8]$.

Therefore, the aim of this study was to evaluate the prevalence of bilateral idiopathic CTS among manual workers. Subject to assessment was also the correlation between symptoms duration and their bilaterality, the severity of electrophysiological changes among idiopathic subjects, and nerve conduction study (NCS) findings in the asymptomatic hands of patients with unilateral CTS.

Knowledge of the natural course of the idiopathic CTS and/or asymptomatic NCS findings of median neuropathy at the wrist may contribute to a more accurate and comprehensive assessment of patients, and influence the schedule of preventive occupational health care.

\section{MATERIAL AND METHODS}

A total of 332 patients ( 288 females, 44 males; mean age $52 \pm 7$ years) who were admitted to the Occupational Medicine Department, the Nofer Institute of Occupational Medicine (NIOM), with suspected occupational CTS were examined by a neurologist and an occupational medicine physician. Each patient was classified into a job category group, and individual job tasks were assessed.

The study protocol was approved by the Bioethics Committee of NIOM (Decision No. 10/2010 of November 26,
2010). Each participant received comprehensive oral and written information about the study.

To be enrolled in the study, the subjects needed to be 25-70 years old, sign an informed consent form, undergo NCS, and satisfy the clinical and electrophysiological criteria of CTS. The clinical diagnosis criteria [9] included a history of:

a) nocturnal or activity-related pain or paresthesia limited to the hand,

b) sensory deficit in median nerve distribution,

c) isolated weakness and/or atrophy of the median innervated thenar muscle,

d) positive Tinel's or Phalen's signs.

Carpal tunnel syndrome was diagnosed when a) and one or more of the b)-d) criteria were present. The NCS of the right and left median and ulnar nerves was performed according to the guidelines of the American Association of Electrodiagnostic Medicine (AAEM) [10,11]. It was conducted by a certified clinical neurophysiologist and neurophysiology technician, using Medtronic Keypoint R Net electromyography (EMG) apparatus. Hand temperature was recorded, and both hands were warmed if the midpalmar temperature was $<32^{\circ} \mathrm{C}[12]$.

Distal latency, conduction velocity and amplitude were determined for motor and sensory branches of the median and ulnar nerves. The compound muscle action potentials (CMAPs) of the abductor pollicis brevis (APB) muscle and the abductor digiti minimi (ADM) muscle were recorded using pairs of surface electrodes at a distance of $8 \mathrm{~cm}$ between the wrist and the belly APB and ADM, respectively (APB and ADM latency). Sensory nerve action potentials (SNAPs) were recorded orthodromically, using ring electrodes after stimulation at the index finger, and registered at the wrist for the median nerve, at a distance of $14 \mathrm{~cm}$ between the stimulator and the active surface electrodes. For the ulnar nerve, SNAPs were obtained in the same way at a distance of $13 \mathrm{~cm}$ between the stimulator at the fifth finger and the active electrode at the wrist. 
Additionally, assessments were made of:

- the difference between median and ulnar sensory latencies from digit 4 stimulation, with a fixed distance of $14 \mathrm{~cm}$ (D4M-D4U) [9], where values above $0.4 \mathrm{~ms}$ were considered abnormal $[13,14])$, and/or

- the second lumbrical-interosseous distal motor latency difference (2LI-DML) (I2) with a fixed distance of $10 \mathrm{~cm}$ between the stimulator and the active electrode [15], where values above $0.6 \mathrm{~ms}$ were assumed to be abnormal [16].

All latencies were measured up to the onset of CMAP and the initial negative peak of SNAP. As regards NCS parameters, the normal values for age were based on a previous study of healthy subjects recruited from NIOM's staff and other volunteers [17]. The abnormal values were defined as more than 2 standard deviations of the normal mean values. The normal laboratory values were:

- for median distal motor latency $\leq 4.2 \mathrm{~ms}$,

- for median distal sensory latency $\leq 3.6 \mathrm{~ms}$,

- for ulnar distal motor latency $\leq 3.3 \mathrm{~ms}$,

- for ulnar distal sensory latency $\leq 3.5 \mathrm{~ms}$.

The electrophysiological diagnostic criteria for CTS included: prolonged median motor latency $(>4.2 \mathrm{~ms})$ and/or prolonged median sensory latency $(>3.6 \mathrm{~ms})$ at the wrist, combined with increased median minus ulnar motor latency (2LI-DML >0.6 ms) and/or sensory latency difference (D4M-D4U SLD >0.4 ms).

The severity of electrophysiological CTS was categorized following the AAEM electrodiagnostic guidelines, developed by Padua [18,19]: extreme, severe, moderate, mild, minimal and negative CTS.

The exclusion criteria included:

- pregnancy,

- cervical radiculopathy $(\mathrm{C6}, \mathrm{C} 7, \mathrm{C} 8)$,

- brachial plexopathy,

- polyneuropathy,

- any other neuropathy of the upper extremities,
- motor neuron disease,

- spondylotic myelopathy,

- syringomyelia,

- multiple sclerosis,

- any contraindications to undergo NCS.

A history of previous surgical carpal tunnel release was not an exclusion criterion. These patients were considered to have unilateral or bilateral CTS although they did not complain of symptoms in the operated hand. All the patients underwent measurements of blood pressure, heart rate, body temperature, and body mass index (BMI $\left[\mathrm{kg} / \mathrm{m}^{2}\right]$ ). Hematological and biochemical tests, urinalysis, ECG, and X-ray of the wrist joint were done. Depending on the medical indications for expanded diagnostics, immunoassays and other specific serological laboratory tests were carried out to detect other diseases that could be related to CTS. A detailed analysis of workplace exposure was performed to determine a possible occupational etiology of the neuropathy. The subjects' medical history, clinical examination, the evaluation of previous MRI and CT findings as well as NCS findings were used to exclude patients with polyneuropathy, cervical radiculopathy, myelopathy and other mononeuropathy.

The primary outcome measure was the prevalence of bilateral idiopathic CTS. The secondary outcome measures included a correlation between the duration of unilateral and bilateral symptoms of neuropathy; a correlation between the onset of symptoms in the unilateral dominant or non-dominant hand, and the time of developing bilateral CTS; the severity of electrophysiological changes in symptomatic hands; and CNS findings for asymptomatic hands of the patients with unilateral CTS.

The distribution of variables such as age and CTS symptoms duration was analyzed for normality using the Shapiro-Wilk test. The nonparametric Mann-Whitney U test was used to evaluate statistically significant differences (at $\mathrm{p}<0.05)$ (SPSS version 21.0). 


\section{RESULTS}

A group of 332 patients (288 females, 44 males), mean age $52 \pm 7$ years, were found to satisfy the clinical criteria for CTS. A total of 258 patients were excluded from the study because of associated neuropathies $(\mathrm{N}=34)$ or any other conditions that could be associated with CTS ( $\mathrm{N}=224)$ (Table 1). In view of the possible influence of job tasks on CTS development, 18 patients (mean age $46 \pm 7$ years) with diagnosed occupational CTS (an average time of job task exposure $20.2 \pm 10.3$ years) were excluded after a job task analysis. As many as 74 patients, all right-handed, were found to suffer from idiopathic CTS. A total of 70 patients had previous surgical decompression of the median nerve at the wrist ( 27 of the right, 12 of the left, and 31 of both hands). These patients were included in the study and considered as either bilateral or unilateral CTS subjects, depending on the past and present clinical and electrophysiological findings. In 15 patients, CTS concerned only the right hand (the unilateral right CTS group, UNI-R), in 4 patients only the left hand (the unilateral left CTS group, UNI-L group), and in 55 patients both hands (the bilateral CTS group, BIL) (Figure 1).
The final analysis covered 55 patients with bilateral CTS, 15 patients with unilateral right-hand CTS, and 4 patients with unilateral left-hand CTS. Table 2 shows clinical data for the 3 study groups which did not differ significantly in terms of age (Table 3).

The subjects with bilateral complaints reported that they had suffered from CTS for 4.0 years $(\mathrm{Me}=3)$ on average, which was significantly longer than for the subjects suffering from right-hand CTS (1.7 years) $(\mathrm{Me}=2)$ $(p=0.002)$ (Figure 2). The subjects with unilateral lefthand CTS reported having neuropathy symptoms for 2.8 years $(\mathrm{Me}=1.2)$ on average, but the comparison of symptoms duration between the groups with bilateral and unilateral left-hand CTS, and between those with the unilateral right- and left-hand CTS, did not reveal significant differences (Table 3).

In 41 patients with bilateral CTS, the symptoms lasted for more than 1 year, whereas only 14 patients complained of bilateral symptoms persisting for a shorter time. Twenty patients reported that the symptoms had developed in the other hand after $1.8 \pm 1.5$ SD years on average. In 14 patients, the symptoms appeared in the right

Table 1. Patients with carpal tunnel syndrome (CTS) and coexisting systemic factors as well as diseases reported at baseline or diagnosed in the course of the study evaluating the prevalence of bilateral idiopathic CTS among manual workers, in a group of 224 patients not classified as idiopathic CTS, Łódź, Poland

\begin{tabular}{|c|c|}
\hline Factor & $\begin{array}{c}\text { Participants } \\
(\mathrm{N}=224) \\
{[\mathrm{n}(\%)]}\end{array}$ \\
\hline Obesity (body mass index $\geq 30 \mathrm{~kg} / \mathrm{m}^{2}$ ) & $96(42.86)$ \\
\hline Thyroid diseases/endocrinopathy & $82(36.61)$ \\
\hline Hormonal agents, oophorectomy & $49(21.88)$ \\
\hline Rheumatoid arthritis, systemic diseases & $19(8.48)$ \\
\hline Diabetes & $36(16.07)$ \\
\hline Hand/wrist trauma/space occupying lesion/carpometacarpal (CMC) arthritis & $11(4.91)$ \\
\hline Gout & $5(2.23)$ \\
\hline Nonspecific tendovaginitis & $8(3.57)$ \\
\hline Occupational origin of carpal tunnel syndrome & $18(8.04)$ \\
\hline Several associated conditions & $111(49.55)$ \\
\hline
\end{tabular}




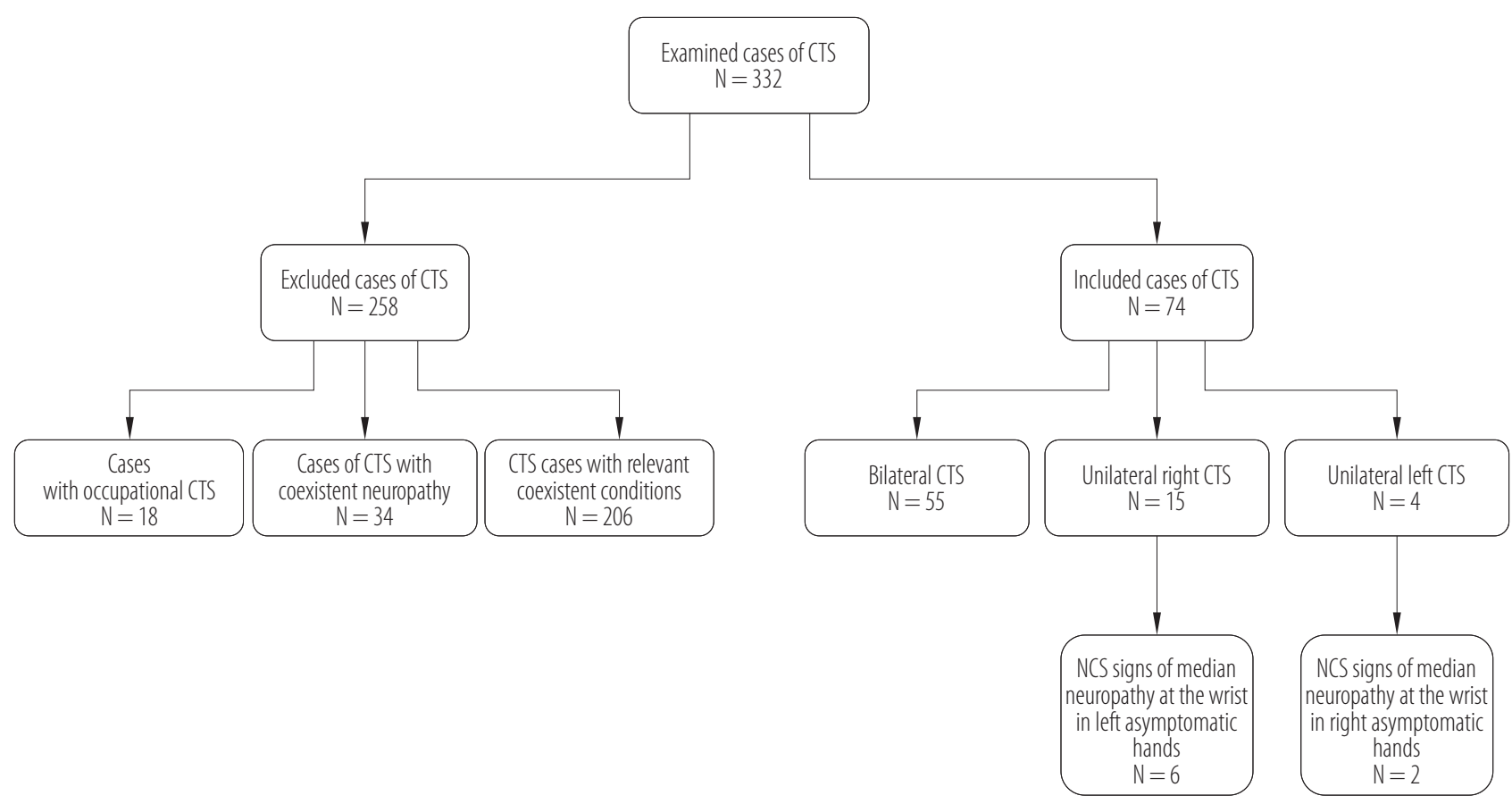

Figure 1. Patients with diagnosed carpal tunnel syndrome (CTS), meeting the goal of the study evaluating the prevalence of bilateral idiopathic CTS among manual workers ( $\mathrm{N}=332)$, Łódź, Poland

Table 2. Clinical data of the 3 studied groups of patients suffering from idiopathic bilateral, unilateral right and unilateral left carpal tunnel syndrome (CTS) in the study evaluating the prevalence of bilateral idiopathic CTS among manual workers, Lódź, Poland

\begin{tabular}{|c|c|c|c|c|}
\hline \multirow{2}{*}{ Variable } & \multicolumn{4}{|c|}{$\begin{array}{l}\text { Participants } \\
(\mathrm{N}=74)\end{array}$} \\
\hline & $\begin{array}{c}\text { bilateral CTS group } \\
\qquad(\mathrm{N}=55)\end{array}$ & $\begin{array}{l}\text { unilateral right CTS group } \\
\qquad(\mathrm{N}=15)\end{array}$ & $\begin{array}{l}\text { unilateral left CTS group } \\
\qquad(\mathrm{N}=4)\end{array}$ & total \\
\hline \multicolumn{5}{|l|}{$\operatorname{Sex}[n]$} \\
\hline women & 47 & 14 & 2 & 63 \\
\hline men & 8 & 1 & 2 & 11 \\
\hline \multicolumn{5}{|l|}{ Age [years] } \\
\hline $\mathrm{M} \pm \mathrm{SD}$ & $52.3 \pm 7.7$ & $50.4 \pm 7.7$ & $51.0 \pm 6.9$ & $51.8 \pm 7.6$ \\
\hline $\min .-\max$ & $31-68$ & $33-59$ & $42-59$ & $31-68$ \\
\hline $\mathrm{Me}$ & 55.0 & 50.0 & 51.5 & 54.0 \\
\hline kurtosis & 0.845 & 0.126 & 1.500 & 0.506 \\
\hline \multicolumn{5}{|c|}{ Duration of symptoms [years] } \\
\hline $\mathrm{M} \pm \mathrm{SD}$ & $4.0 \pm 2.7$ & $1.7 \pm 0.4$ & $2.8 \pm 3.4$ & $3.4 \pm 2.5$ \\
\hline $\min .-\max$ & $1-10$ & $1-2$ & $1-8$ & $1-8$ \\
\hline $\mathrm{Me}$ & 3.0 & 2.0 & 1.2 & 3.0 \\
\hline kurtosis & -0.798 & -0.734 & 3.901 & -0.308 \\
\hline
\end{tabular}


Table 3. Comparison of age and duration of carpal tunnel syndrome (CTS) symptoms between the groups involved in the study evaluating the prevalence of bilateral idiopathic CTS among manual workers, Łódź, Poland

\begin{tabular}{lccc}
\hline \multirow{2}{*}{ Variable } & \multicolumn{3}{c}{ Group comparison } \\
\cline { 2 - 4 } & BIL vs. UNI-R & BIL vs. UNI-L & UNI-R vs. UNI-L \\
\hline Age* $^{*} \mathrm{U}=354.5(\mathrm{p}=0.405)$ & $\mathrm{U}=94.0(\mathrm{p}=0.628)$ & $\mathrm{U}=28.5(\mathrm{p}=0.880)$ \\
Duration of CTS symptoms* & $\mathrm{U}=198.5(\mathrm{p}=0.002)$ & $\mathrm{U}=77.0(\mathrm{p}=0.313)$ & $\mathrm{U}=23.0(\mathrm{p}=0.427)$ \\
\hline
\end{tabular}

BIL - the bilateral carpal tunnel syndrome group; UNI-R - the unilateral right carpal tunnel syndrome group; UNI-L - the unilateral left carpal tunnel syndrome group.

* Analyzed by Mann-Whitney U test.

dominant hand, and in 6 in the left non-dominant hand. The author compared the duration of unilateral symptoms up to the manifestation of bilaterality in these 2 groups. In 14 patients whose CTS had developed in the right dominant hand, the symptoms in the opposite hand developed after $1.6 \pm 0.6$ years $(\mathrm{Me}=2$, range $1-3$ ) and did not differ significantly from the findings for the 6 patients with initially left-hand CTS $-1.2 \pm 0.4$ years $(\mathrm{Me}=1.0$, range $1-2), U=25.50(p=0.244)$. A clinical analysis of the patients with bilateral CTS showed bilateral manifestation of early-stage neuropathy in 35 patients.

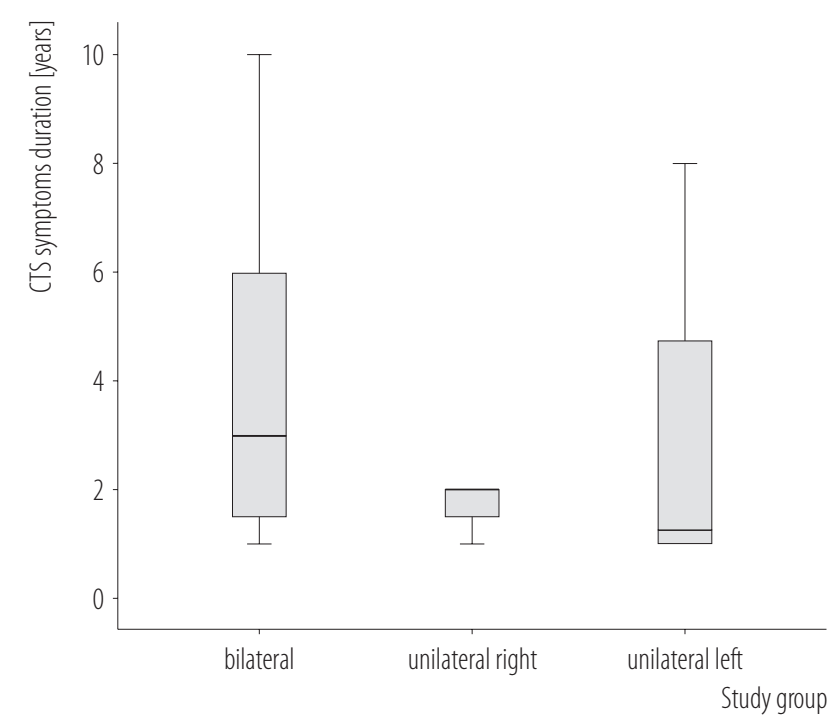

Figure 2. Duration of carpal tunnel syndrome (CTS) symptoms in the study evaluating the prevalence of bilateral idiopathic CTS among manual workers $(\mathrm{N}=332)$, Łódź, Poland
In 8 patients with unilateral CTS, the NCS findings revealed signs of median neuropathy at the wrist in the asymptomatic hands. In 15 patients from the UNI-R group and in 4 patients from the UNI-L group, the electrodiagnostic tests were positive in 6 left and 2 right asymptomatic hands. According to the neurophysiologic classification, these asymptomatic hands showed minimal changes in 1 hand (the UNI-R group), mild in 6 hands ( 2 in the UNI-L group and 4 in the UNI-R group) and moderate in 1 hand (the UNI-R group). All the 8 subjects for whom the electrodiagnostic test revealed median neuropathy in asymptomatic hands had undergone the open carpal tunnel release procedure in the symptomatic right and left hands, at respectively $1.6 \pm 1.5$ and $2.3 \pm 1.8$ years preceding the study. Therefore, the author was unable to compare the severity of electrophysiological changes in the symptomatic CTS hands with the NCS findings for the asymptomatic hands of the patients with unilateral disorders, which was supposed to be one of the objectives of the present study.

\section{DISCUSSION}

To the best of the author's knowledge, this is the first study evaluating the bilaterality of idiopathic CTS in a Polish population of manual workers.

The prevalence of idiopathic CTS among the patients involved in the study was estimated to be $24.3 \%$, in contrast to $43.2-50.0 \%$ as reported by other researchers [6,20]. It is well known that mononeuropathy may directly manifest as a bi- 
lateral condition or turn from a unilateral to bilateral neuropathy. A meta-analysis of the literature reports published in 1950s and 1960s revealed that the bilaterality of CTS symptoms approximated 55\% [21]. In 1970s, Phalen [22] and Bendler [23] described the CTS incidence as 56\% and 61\% of bilateral cases, respectively. Reinstein [1] was the first to analyze the association between hand dominance and idiopathic median neuropathy at the wrist, and he recorded a bilaterality rate of about $76 \%$. To this date, only 2 studies have focused on the incidence of bilateral idiopathic CTS [7,8]. Padua et al. [7] reported that $87 \%$ of patients presented bilateral CTS symptoms of idiopathic etiology. Median NCS findings revealed that about $50 \%$ of patients had unilateral neurophysiologic abnormalities in the asymptomatic hands. In a retrospective study, Bagatur and Zorer [8] noted bilateral CTS symptoms in $59 \%$ of cases, but the neurophysiologic abnormalities of the median nerve at the wrist concerned $66 \%$ of the asymptomatic hands.

The present findings are in concordance with the above reports. A majority of the subjects had bilateral CTS (74.3\%), with more subjects presenting a unilateral righthand than left-hand condition: $20.5 \%$ vs. $5.4 \%$. All of the study participants were right-handed. In the unilateral groups, $42.1 \%$ were found to have abnormal median NCS findings in the contralateral asymptomatic hand.

The findings of the studies discussed above showed a positive correlation between symptoms duration and the bilateral manifestation of CTS. Padua et al. [7] reported a mean duration of bilateral CTS symptoms of 3.7 years, in contrast to a shorter duration of the right- or left- hand neuropathy, amounting to 0.8 and 0.6 years, respectively. Bagatur and Zorer [8] reported that in 41 out of 54 patients initially suffering from unilateral CTS, the symptoms in the opposite hand developed after a mean interval of 3.2 years. The author of this study found a similar positive correlation between bilateral CTS and symptoms duration. In the patients with bilateral CTS, the symptoms persisted significantly longer than in those with the unilateral right-hand condition $(p=0.002)$. Although the duration of symptoms in the patients with left-hand CTS tended be shorter than in those with bilateral CTS, the differences did not reach statistical significance $(p=0.313)$, possibly due to a small population sample. In this study, the patients could not accurately define when the symptoms had manifested in the opposite hand, but $35.1 \%$ considered this could have been $1.5 \pm 0.5$ years after the onset of symptoms. In $64.8 \%$ of the patients, bilateral symptoms occurred simultaneously. The author did not find any significant differences between the duration of CTS symptoms in the unilateral dominant or non-dominant hand and the time when the bilaterality had manifested. This finding is consistent with the results reported by Padua et al. [7].

This study has had several limitations. Firstly, the author was unable to analyze the correlation between the severity of clinical and neurophysiologic findings in the asymptomatic hands of the patients with unilateral CTS. This was mainly due to the fact that as many as $95.9 \%$ of the patients examined had a history of previous surgical decompression of the median nerve at the wrist. Secondly, the idiopathic origin of CTS has remained controversial: some authors report local pathological changes leading to mononeuropathy [24-27], while others postulate that when the CTS is unilateral and its etiology is not clear, a space occupying lesion should be suspected [28]. Plain radiographs and computed tomography (CT) are of limited diagnostic value except for the evaluation of osseous carpal stenosis and soft tissue calcifications. Computed tomography may be preferred for bone-related pathological conditions. Ultrasonogram imaging is actually recommended as complementary testing in diagnosing CTS jointly with electroneurography. A cross-sectional area (CSA) measurement of the medial nerve in the wrist is the most common method of ultrasound for diagnosis of CTS. In a recent meta-analysis, the most frequent CSA cutoff point for detecting CTS was $8.5-10 \mathrm{~mm}^{2}$ at the level of the pisiform [29]. Additionally, some reports have shown that ultrasonogra- 
phy correlates with electrophysiological measurements and even allows to estimate the severity of CTS [30]. El Miedany et al. [31] recommended cross-section area cutoff points that discriminate between different grades of CTS severity as $10-13 \mathrm{~mm}^{2}$ for mild symptoms, $13-15 \mathrm{~mm}^{2}$ for moderate symptoms, and $>15 \mathrm{~mm}^{2}$ for severe patients. Koyuncuoglu et al. [32] found abnormal median nerve CSA in $30 \%$ of 59 wrists with a clinical diagnosis of CTS patients and normal NCS, using a median nerve CSA $>10.5 \mathrm{~mm}^{2}$ at the carpal tunnel inlet as the diagnostic cutoff.

Magnetic resonance imaging (MRI) is a sensitive diagnostic tool providing a detailed image of the median nerve along with other neural, vascular, and bone structures. Due to related costs and more time-consuming measurements, MRI is rarely used in CTS diagnosing and is preferred for diagnosing soft tissue-related pathological conditions. This technique is recommended especially in unilateral CTS subjects that belong to a young age group, are of male gender, have recurrent symptoms, or lack any pronounced predisposing factors, and in patients with partial or no recovery despite surgical intervention [33].

During the study, the author performed wrist X-ray and analyzed the findings of ultrasonogram imaging for CTSaffected hands before the surgery, along with medical data concerning previous surgical decompression of the median nerve at the wrist. She did not find any medical records indicating any space occupying lesions, or anatomical variations or intraoperative anomalies of the carpal tunnel, in either bilateral or unilateral CTS patients. However, the lack of precise measurements via CT, MRI or ultrasonogram imaging before the surgery constrained the assessment of any anatomical variations in carpal tunnel dimensions in the study population, as well as the assessment of the possible associations with CTS bilaterality or unilaterality.

Thirdly, the present project was a single-center, cross-sectional observation study with no control group (e.g., workers handling non-manual tasks), which makes it of little use for predicting CTS development. Moreover, the au- thor could not elicit accurate data on the time lapse between the manifestation of CTS symptoms in one hand and the development of bilaterality, due to an imperfect recollection of data by the subjects. Apart from that, the small number of subjects with CTS in the left non-dominant hand could have an impact on the findings. All these issues significantly constrain the applicability of the findings for predicting the time interval between the subclinical CTS and the full-blown condition.

With regard to the strong points, worthy of note is the fact that the study included a detailed analysis of occupational exposure, taking account of the possible influence that the specific job tasks may have had on CTS development in the dominant and non-dominant hand or in both hands. The author excluded patients with an occupational origin of the mononeuropathy. The 74 patients eventually included in the study had not been involved in long-lasting activities that required an extensive, forceful, repeated use of the hands and wrists, a repetitive forceful use of fingers in a pinch grip, a constant firm gripping of objects, or a regular use of vibrating hand-held power tools.

In the idiopathic cases, an increased daily activity of the dominant hand seems to be a contributing factor in CTS development and its bilaterality. It is plausible that shifting most of the everyday tasks from the CTS-affected hand to the asymptomatic hand may be a significant risk factor for developing, at first, the electrophysiological and then clinical signs of median neuropathy at the wrist. Apart from that, the presence of the peripheral and central sensitization is a well-documented mechanism underlying the development of bilateral CTS symptoms, probably related to neuroplastic changes in the somatosensory brain cortex [34]. On the other hand, the above hypothesis does not explain the simultaneous manifestation of bilaterality in idiopathic CTS cases. It is postulated that an immunohistochemical factor may be involved in the pathogenesis of the median nerve injury at the wrist $[35,36]$ and its bilateral pattern. 
These possible pathomechanisms should be taken into account in the occupational assessment procedure, especially for the work-related bilateral CTS. The CTS developing in the contralateral hand after several months' latency from CTS manifestation in the hand that had been constantly used for performing job tasks may be associated with an increased compensation activity of the opposite hand and/ or with the central sensitization process.

The findings of the study support the concept of idiopathic CTS as a bilateral disorder as well as the assumption that almost all cases of unilateral CTS will develop into its bilateral form, and the process is only a matter of time. In view of the above, the author presumes that clinicians need to extend their diagnostic and therapeutic activities beyond detecting and managing local tissue pathologies in CTS patients. They should focus their intervention on restoring the manual capabilities in order to prevent the risk of central sensitization as well as bilaterality of CTS symptoms.

Therefore, nerve conduction studies in patients with unilateral CTS should also include examinations of the asymptomatic hand. These patients should be carefully monitored for clinical and neurophysiological conditions that may lead to a future development of classic CTS. Considering the possible influence of occupational factors in CTS etiology, the cooperation of general practitioners, neurologists and other specialists with occupational physicians is crucial in preventive occupational health care.

It is a good occupational health care practice that CTS patients cannot continue job tasks demanding a forceful use of the hand, repetitive motion, an awkward position of the hand, and vibration exposure in the affected hand until full recovery. Any neurographical signs of median neuropathy at the wrist in the asymptomatic hand should imply relevant ergonomical intervention assuming a precautionary line, and highly repetitive wrist-hand work should be avoided by an ergonomic design of tasks and tools, and by the appropriate scheduling of work and rest periods.

\section{CONCLUSIONS}

A prospective study of the newly-diagnosed idiopathic CTS cases, with nerve conduction studies and wrist imaging, according to uniform procedures for data collection, examination, and analysis, would help assess the prevalence of bilaterality of idiopathic CTS and define the moment of conversion from a unilateral to bilateral disorder.

\section{ACKNOWLEDGMENTS}

The author expresses her deep gratitude towards Prof. Jolanta Walusiak-Skorupa for giving her an opportunity to conduct this study, and for her valuable suggestions and critical review of the draft manuscript. The author further expresses her appreciation to all the occupational health specialists from the Occupational Diseases Department, NIOM, for their assistance throughout the study. She would also like to thank Dorota Kosik, the technical assistant, for conducting nerve conduction studies, and Maciej Guz, M.Sc., for performing the statistical analysis.

\section{REFERENCES}

1. Reinstein L. Hand dominance in carpal tunnel syndrome. Arch Phys Med Rehabil. 1981;62(5):202-3.

2. Zambelis T, Tsivgoulis G, Karandreas N. Carpal Tunnel Syndrome: Associations between risk factors and laterality. Eur Neurol. 2010;63:43-7, https://doi.org/10.1159/000268165.

3. Janz C, Brock M, Kern BC. Bilateral carpal tunnel syndromesurgical therapy-prognostic factors and results. Zentralbl Neurochir. 1995;56(2):88-92.

4. Stanek EJ, Pransky G. Unilateral vs bilateral carpal tunnel challenges and approaches. Amer J Industr Med. 1996;29:669-78, https://doi.org/10.1002/(SICI)1097-0274(199606)29:6<669:: AID-AJIM11>3.0.CO;2-Y.

5. Bonfiglioli R, Mattioli S, Spagnolo MR, Violante FS. Course of symptoms and median nerve conduction values in workers performing repetitive jobs at risk for carpal tunnel syndrome. Occup Med (Lond). 2006;56(2):115-21, https://doi. org/10.1093/occmed/kqj007. 
6. Aroori S, Spence RA. Carpal tunnel syndrome. Ulster Med J. 2008;77(1):6-17.

7. Padua L, Padua R, Nazzaro M, Tonali P. Incidence of bilateral symptoms in carpal tunnel syndrome. J Hand Surg [Br]. 1998;23:603-6.

8. Bagatur AE, Zorer G. The carpal tunnel syndrome is a bilateral disorder. J Bone Joint Surg Br. 2001;83(5):655-8.

9. Rempel D, Evanhoff B, Amadio PC. Consensus criteria for classification of CTS in epidemiological studies. Am J Public Health. 1998;88:1447-51, https://doi.org/10.2105/ajph. 88.10.1447.

10. Jablecki CK, Andary MT, Floeter MK, Miller RG, Quartly CA, Vennix MJ, et al. Practice parameter: Electrodiagnostic studies in carpal tunnel syndrome. Report of the American Association of Electrodiagnostic Medicine, American Academy of Neurology, and the American Academy of Physical Medicine and Rehabilitation. Neurology. 2002;58(11):158992, https://doi.org/10.1212/WNL.58.11.1589.

11. Practice parameter: electrodiagnostic studies in ulnar neuropathy at the elbow. Summary statement of the American Association of Electrodiagnostic Medicine American Academy of Neurology and American Academy of Physical Medicine and Rehabilitation. Neurology. 1999;10;52(4):688-90, https://doi.org/10.1212/WNL.52.4.688.

12. Denys EH. AAEM minimonograph no.14. The influence of temperature in clinical neurophysiology. Muscle Nerve. 1995;14(9):795-811, https://doi.org/10.1002/mus.880140902.

13. Oh SJ. Clinical Electromyography: Nerve Conduction Studies. 2nd ed. Baltimore: Lippincott Williams and Wilkins; 1993.

14. Johnson EW, Kukla RD, Wongsam PE, Piedmont A. Sensory latencies to the ring finger: Normal values and relation to carpal tunnel syndrome. Arch Phys Med Rehab. 1981;62:206-8.

15. Preston DC, Logigian EL. Lumbrical and interossei recording in carpal tunnel syndrome. Muscle Nerve. 1992;15(11): 1253-7, https://doi.org/10.1002/mus.880151106.

16. Al-Shekhlee A, Fernandes Filho JA, Sukul D, Preston DC. Optimal recording electrode placement in the lumbrical- interossei comparison study. Muscle Nerve. 2006;33(2):28993, https://doi.org/10.1002/mus.20488.

17. Lewańska M, Wągrowska-Koski E, Walusiak-Skorupa J. Etiological factors for developing carpal tunnel syndrome in people who work with computers. Med Pr. 2013;64(1):37-45, https://doi.org/10.13075/mp.5893/2013/0005.

18. Padua L, LoMonaco M, Gregori B. Neurophysiological classification and sensitivity in 500 carpal tunnel syndrome hands. Acta Neurol Scand. 1997;96(4):211-7, https://doi.org/10.1111/ j.1600-0404.1997.tb00271.x.

19. Padua L, LoMonaco M, Padua R. Neurophysiological classification of carpal tunnel syndrome: assessment of 600 symptomatic hands. Ital J Neurol Sci. 1997;18(3):145-50, https:// doi.org/10.1007/BF02048482.

20. Stevens JC, Beard CM, O'Fallon WM, Kurland LT. Conditions associated with carpal tunnel syndrome. Mayo Clin Proc. 1992;67(6):541-8, https://doi.org/10.1016/s0025-6196(12) 60461-3.

21. Kelsey JL. Disorders of the extremities. In: Moore J, editor. Epidemiology of Musculosceletal Disorders. New York: Oxford Universisty Press; 1982.

22. Phalen GS. The carpal tunnel syndrome: clinical evaluation of 598 hands. Clin Orthop. 1972;83:29-40, https://doi. org/10.1097/00003086-197203000-00007.

23. Bendler EM, Greenspun B, Yu J, Erdmann WJ. Bilaterality of carpal tunnel syndrome. Arch Phys Med Rehabil. 1977;58:362-4.

24. Watson-Jones R. Primary nerve lesions in injuries of the elbow and wrist. J Bone Joint Surg. 1930;12:121-40.

25. Phalen GS, Kendrick JI. Compression neuropathy of the median nerve in the carpal tunnel. JAMA. 1957;164: 524-30.

26. Dekel S, Papaioannou T, Rushworth G, Coates R. Idiopathic carpal tunnel syndrome caused by carpal stenosis. Br Med J. 1980:280(6227):1297-9, https://doi.org/10.1136/ bmj.280.6227.1297.

27. Lim PG., Tan S, Ahmad TS. The role of wrist anthropometric measurement in idiopathic carpal tunnel syndrome. 
Hand Surg Eur. 2008;33(5):645-7, https://doi.org/10.1177/ 1753193408093326.

28. Nakamichi K, Tachibana S. Unilateral carpal tunnel syndrome and space-occupying lesions. J. Hand Surg. 1993;18:748-9.

29. Torres-Costoso A, Martínez-Vizcaíno V, Álvarez-Bueno C, Ferri-Morales A, Cavero-Redondo I. Accuracy of ultrasonography for the diagnosis of carpal tunnel syndrome: a systematic review and meta-analysis. Arch Phys Med Rehabil. 2018;99(4): 758-65.e10, https://doi.org/10.1016/j.apmr.2017.08.489.

30. Karadag YS, Karadag Ö, Cicekli E Oztürk S, Kiraz S, Ozbakir S, et al. Severity of carpal tunnel syndrome assessed with high frequency ultrasonography. Rheumatol Int 2010; 30:761-5, https://doi.org/10.1007/s00296-009-1061-x.

31. El Miedany YM, Aty SA, Ashour S. Ultrasonography versus nerve conduction study in patients with carpal tunnel syndrome: substantive or complementary tests? Rheumatology. 2004; 43(7):887-95, https://doi.org/10.1093/rheumatology/keh190.

32. Koyuncuoglu HR, Kutluhan S, Yesildag A, Oyar O, Guler K, Ozden A. The value of ultrasonographic measurement in carpal tunnel syndrome in patients with negative electrodiagnostic tests. Eur J Radiol. 2005;56(3):365-9.

33. Onen MR, Kayalar AE, Ilbas EN, Gokcan R, Gulec I, Naderi S. The Role of Wrist Magnetic Resonance Imaging in the Differential Diagnosis of the Carpal Tunnel Syndrome. Turk Neurosurg. 2015;25(5):701-6, https://doi.org/10.5137/10195149.JTN.10754-14.2.

34. De-la-Llave-Rincon AI, Puentedura EJ, Fernandez-de-lasPenas C. New advances in the mechanisms and etiology of carpal tunnel syndrome. Discov Med. 2012;13(72):343-8.

35. Donato D, Galasso O, Valentino P, Conforti F, Zuccala V, Russo E, et al. Pathological findings in subsynovial connective tissue in idiopathic carpal tunnel syndrome. Clin Neuropathol. 2009;28(2):129-35.

36. Chikenji T, Gingery A, Zhao Ch, Passe SM, Ozasa Y, Larson D, et al. Transforming growth factor- $\beta$ (TGF- $\beta$ ) expression is increased in the subsynovial connective tissues of patients with idiopathic carpal tunnel syndrome. J Orthop Res. 2014;32(1):116-22, https://doi.org/10.1002/ jor.22485.

This work is available in Open Access model and licensed under a Creative Commons Attribution-NonCommercial 3.0 Poland License - http://creativecommons.org/ licenses/by-nc/3.0/pl/deed.en. 